\title{
МАКРОЭКОНОМИЧЕСКИЕ ПРОБЛЕМЫ ФОРМИРОВАНИЯ НАЛОГОВОГО КЛИМАТА
}

\section{MACROECONOMIC PROBLEMS OF THE TAX CLIMATE FORMATION}

L. Savina

Summary. The tax climate is the most important component of the national security of any country, since it forms the revenue part of the state. The growth of tax revenues in the state increases the degree of social benefits, as well as employees of budget structures, which accordingly affects the growth of public demand for goods, services and works sold in the state. The opposite situation will be observed with a decrease in tax revenues of the budget. At the same time, an increase in the country's tax revenues may be associated with an increase in the tax burden on the participants of the tax system, which will negatively affect their commercial activity, and will contribute to a decrease in demand in the country's economic system.

The purpose of the article is to identify the problems of a macroeconomic nature that negatively affect the formation of the tax climate in the country. At the same time, the directions of solving these problems have been identified, which in general will contribute to the formation of an attractive tax climate in Russia.

Keywords: macroeconomic factors, taxes, tax climate, problems, solutions, efficiency.

\section{Обсужление}

H алоги выполняют важную роль в экономике России, обеспечивая финансовыми ресурсами социальные и экономические потребности страны. При этом снижается степень убыточности и бедности населения в России, одновременно создавая баланс стабильности жизни в стране. Однако необходимо реформировать налоговую систему, опираясь на опыт зарубежных стран и учитывая сложности и специфику деятельности российского бизнеса.

Определяя комплексные проблемы налогового климата в стране, стоит дать определение данному понятию. В соответствии с определением, предлагаемым Ткач Е.В., под налоговым климатом определяется вся совокупность факторов, так или иначе воздействующих на ведение бизнеса в стране [1]. Автор считает, что климат - это текущая ситуация, способствующая либо препятствующая деятельности предприятий государства.
Савина Любовь Львовна

Старший преподаватель, Нижегородский институт управления (филиал) Российской академии народного хозяйства и государственной службы при Президенте Российской Федерации Savina_LL@mail.ru

Аннотация. Налоговый климат является важнейшей составляющей национальной безопасности любой страны, поскольку формирует доходную часть государства. Рост налоговых доходов в государстве повышает степень социальных выплат, а также работников бюджетных структур, что соответственно сказывается на росте спроса населения на товары, услуги и работы, реализуемые в государстве. Обратная ситуация будет прослеживаться при снижении налоговых доходов бюджета. В тоже время, увеличение налоговых доходов страны может быть связано с повышением налогового бремени на участников налоговой системы, что негативно скажется на их коммерческой активности, и будет способствовать снижению спроса в экономической системе страны.

Цель статьи заключается в выявлении проблем макроэкономического характера, негативно влияющих на формирование налогового климата в стране. При этом определены направления решения данных проблем, что в целом будет способствовать формированию привлекательного налогового климата в России.

Ключевые слова: макроэкономические факторы, налоги, налоговый климат, проблемы, пути решения, эффективность.

В свою очередь Фишер О.В. определяет налоговый климат страны, как взаимодействие налогового потенциала государства, налоговой системы и налоговых рисков [2]. При этом, чем выше налоговый потенциал и прозрачность налоговой системы, тем ниже уровень налоговых рисков и позитивнее налоговый климат территории.

Комарова В.И. [3] соотносит налоговый климат страны с налоговым механизмом и налоговой политикой государства, которые в совокупности формируют оптимальные условия для развития бизнеса и стабильного пополнения казны, являющейся источником для покрытия социальных нужд страны.

Анализ представленных определений позволяет сделать вывод, что налоговый климат в стране включает в себя все элементы, так или иначе связанные с налогами, воздействующими на бизнес, а значит и стабильность развития экономики. В современных условиях не выработано единого критерия оценки налогового климата 


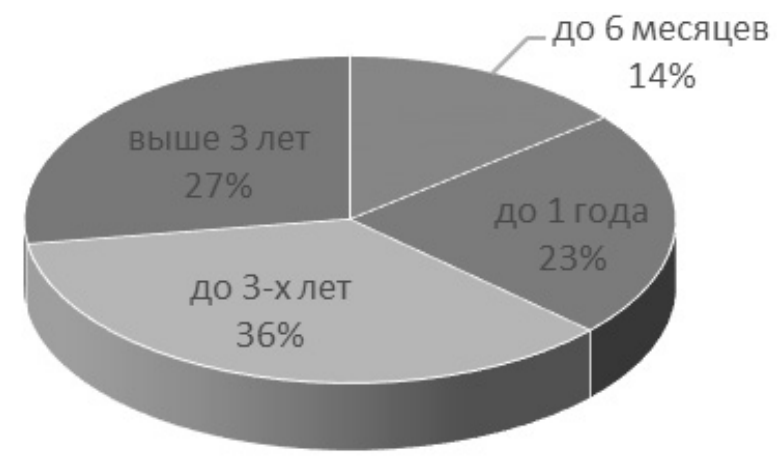

Рис. 1. Распределение опрошенных по сроку ведения своего бизнеса,\% Источник: составлено автором по результатам проведенного опроса

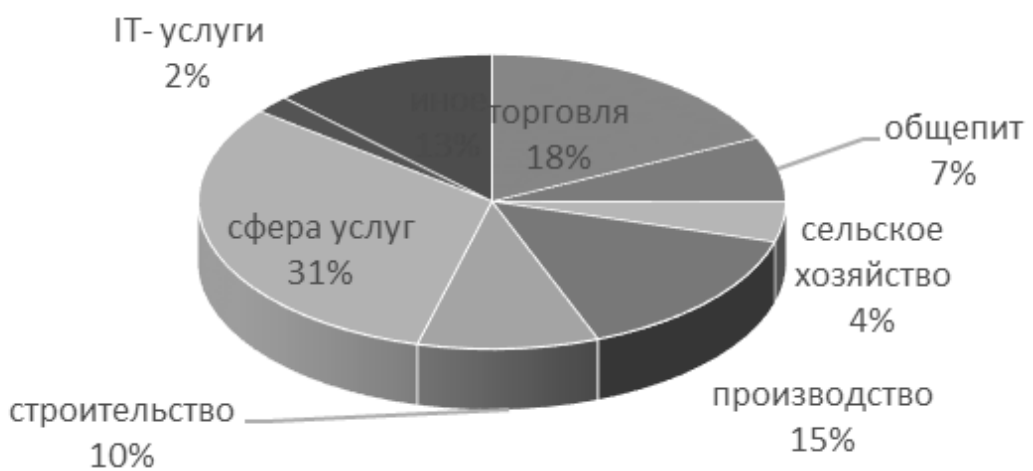

Рис. 2. Распределение респондентов по отраслям промышленности,\% Источник: составлено автором по результатам проведенного опроса

государства. используется набор количественных и качественных характеристик. Однако наиболее точным методом выявления проблем, влияющим на налоговую систему, а значит и налоговый климат государства, являются опросы, проводимые среди представителей бизнеса [4]. Для того чтобы выделить проблемы задействования налоговой системы для достижения максимальной степени привлекательности налогового климата в стране, следует провести опрос среди представителей предпринимательства, являющихся налогоплательщиками.

\section{Время проведения опроса: 20-30 января 2021 г.}

Объем выборочной совокупности: 100 респондентов

Статистическая погрешность данных: по г. Москва $+4,0$

Среди опрошенных 50 организаций работает в форме общества с ограниченной ответственностью, и 50 в форме индивидуального предпринимательства.

30 опрошенных - женщины, 70 - мужчины. Bсе в возрасте 25-45 лет.
В опросе участвовали 100 предприятий, ведущих свою деятельность до 6-ти месяцев, 158 - до 1 года, 250 - до 3-х лет и 192- свыше 3-х лет. Процентное распределение приведено на диаграмме (рисунок 1).

Большая часть опрошенных ведет бизнес более 3-х лет (36\%), что позволяет максимально точно определить спектр экономических угроз предпринимательству. Наличие среди опрошенных предприятий, действующих до 6 месяцев (14\%) позволит более четко определить проблемы, свойственные периоду открытия бизнеса. Распределение респондентов по отраслям приведено на диаграмме (рисунок 2).

Большая часть опрошенных работает в сфере услуг (31\%), что связано с преобладанием числа предприятий данной отрасли в экономике и низкой численности работников большинства из них. В тоже время $18 \%$ респондентов работают в сфере торговли, что также обусловлено спецификой отрасли, в которой большая часть организаций включена в реестр малых предприятий. В производстве работает 15\% опрошенных, среди которых предприятия по производству строительных, полимерных, и других материалов, легкой промышлен- 


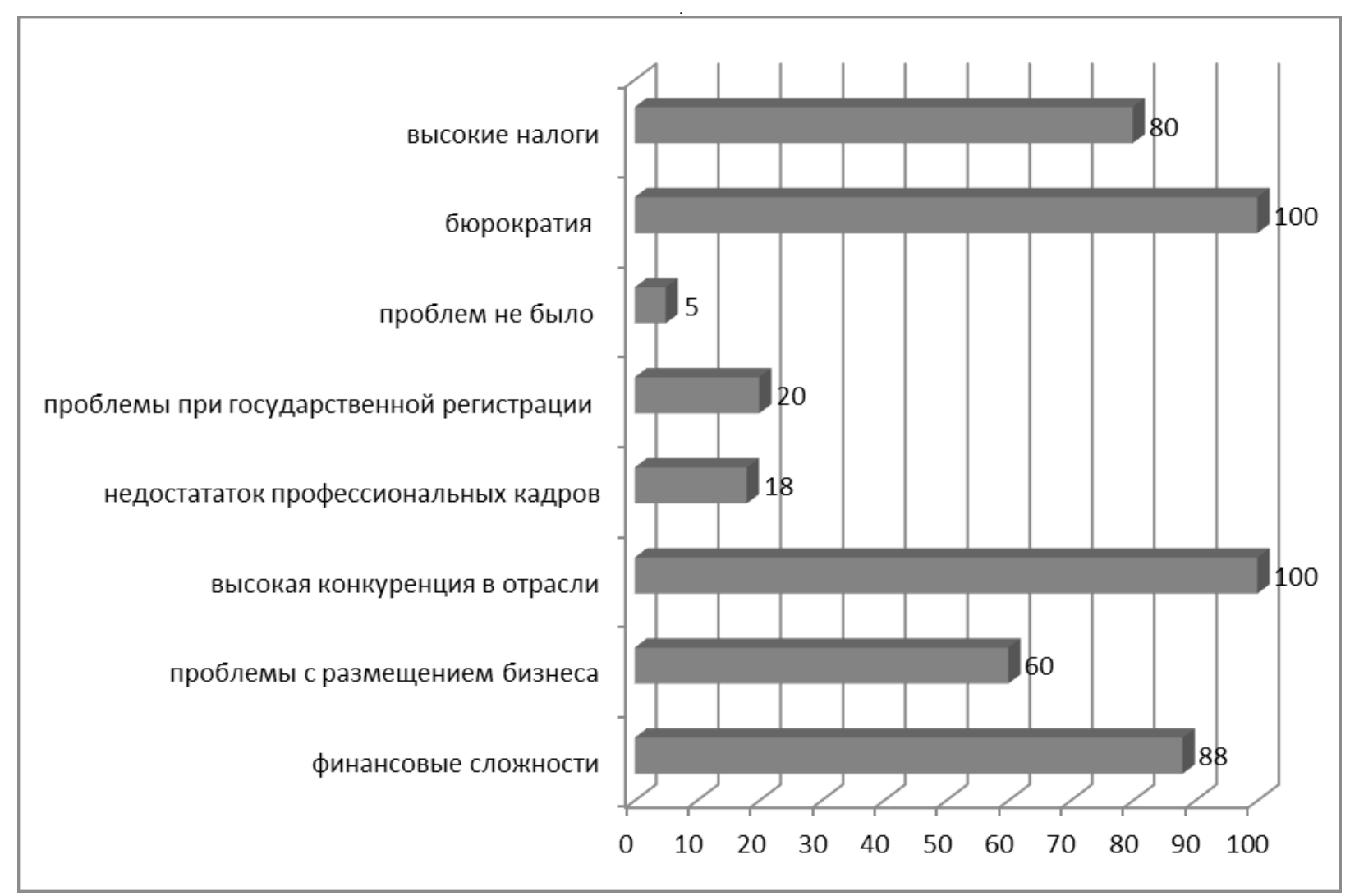

Рис. 3. Распределение ответов на вопрос: «С какими проблемами Вы столкнулись при организации собственного дела?», раз

Источник: составлено автором по результатам проведенного опроса

ности, химической, фармацевтической и других отраслей. Часть опрошенных также работают в сфере общественного питания (7\%), строительства (10\%), прочих услуг (13\%). Таким образом, представленная структура доказывает наличие малых предприятий практически во всех сегментах бизнеса, что еще более существенно обосновывает их значимость в экономике страны.

Отвечая на вопрос «С какими проблемами Вы столкнулись при организации собственного дела?», предпринимателями были даны разные ответы, распределение которых приведено на рисунке 3. Поясним, что многие предприниматели выбирали по несколько вариантов ответов.

Максимальное число опрошенных жаловалось на высокую конкуренцию в отрасли, ее почеркнули 100 раз. В тоже время финансовые трудности, к которым были отнесены и сложности в привлечении заемных ресурсов, недостаток собственного капитала, убытки на первых этапах деятельности, подчеркнули 88 раза. Большая проблема, по мнению высокого числа опрошенных, связана с бюрократическими процедурами, которые необходимы выполнить начинающему предпринимате- лю, чтобы стать участником государственных программ, получить доступ к дешевым финансовым ресурсам, воспользоваться полагающимися им льготами.

80 человек отметили наличие высоких налоговых ставок, которые могли бы быть меньше на первых этапах работы новых предприятий, что доказывает наличие проблем в налоговом климате государства, а также его влиянии на деятельности бизнеса в целом. Далее было предложено пояснить, какие конкретно проблемы предприниматели видят в налоговой сфере. Распределение ответов на вопрос приведено на рисунке 4.

Большая часть представителей бизнеса жалуется на высокие ставки налогов. При этом часто они поясняют, что приходится изыскивать пути снижения налоговой нагрузки, поскольку в противном случае им придётся уйти с рынка.

Далее опрошенным были заданы вопросы по применению ими инструментов по занижению налогов.

Распределение ответов на вопрос приведено на рисунке 5. 
- Высокие ставки НДС

- Сложности в обосновании расходов при применении УСНО

- Высокая налоговая нагрузка по социальным отчислениям

- Низкая граница доходов, облагаемых по системе "патент"

- Высокая ставка налога на прибль

- Высокая ставка на имущественные налоги

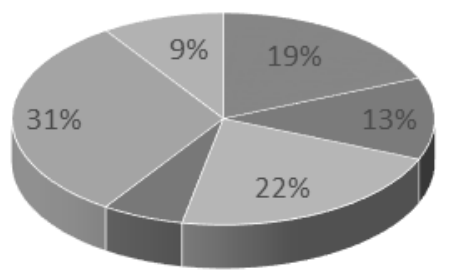

$6 \%$

Рис. 4. Распределение ответов на вопрос по эффективности налоговой системы,\% Источник: составлено автором по результатам проведенного опроса

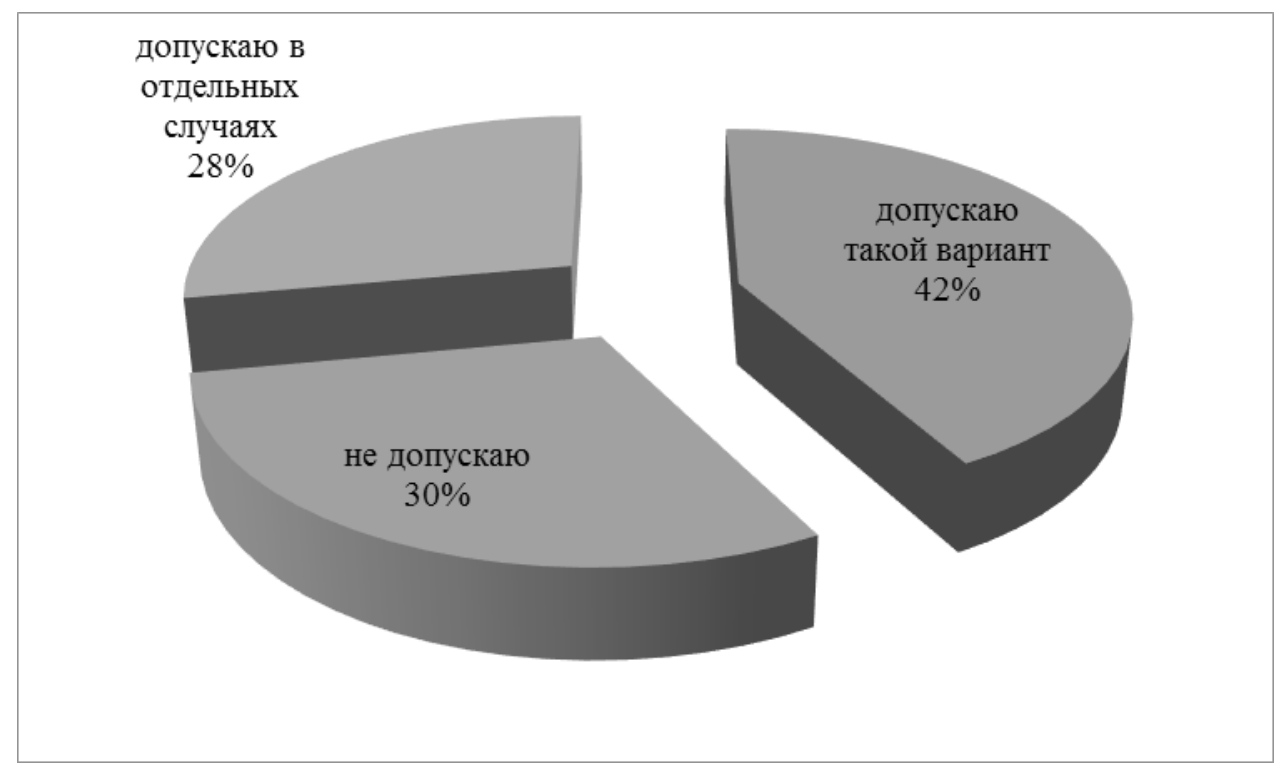

Рис. 5. Распределение ответов на вопрос «Используете ли Вы в своей деятельности варианты незаконной оптимизации налоговой нагрузки?»

Источник: составлено автором по результатам проведенного опроса

Так 42\% опрошенных считают приемлемым ситуацию, когда налоги уплачиваются не в полном объеме, и возможны варианты налоговой оптимизации, которых противоречат закону $21 \%$ полностью уклоняются от уплаты налогов, а 49\% или половина опрошенных не платят их частично. Большая часть опрошенных ссылалась на жесткость и неадекватность налогообложения в стране, невозможность рентабельной работы при полной уплате всех налоговых и прочих платежей.
Распределение ответов на последний вопрос приведено на рисунке 6.

44\% считают получение контрагентами оплату из рук в руки, минуя кассу нормой. Более того, многие из опрошенных склонны утверждать, что повысить свой уровень жизни без нарушения законов невозможно.

Таким образом, проведенный опрос позволяет сделать вывод, что сформированная в России налоговая 


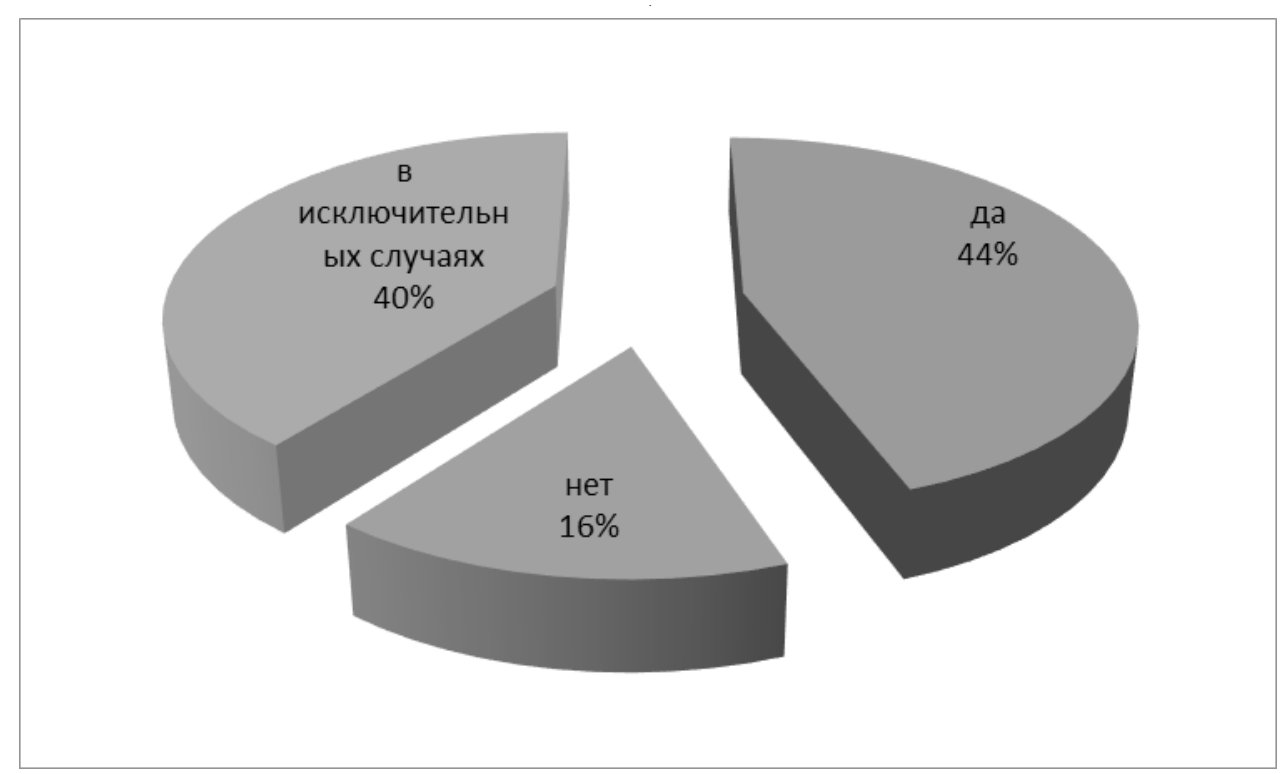

Рис. 6. Распределение ответов на вопрос «Считаете ли Вы отношения «минуя кассу» противоправным деянием?»

Источник: составлено автором по результатам проведенного опроса

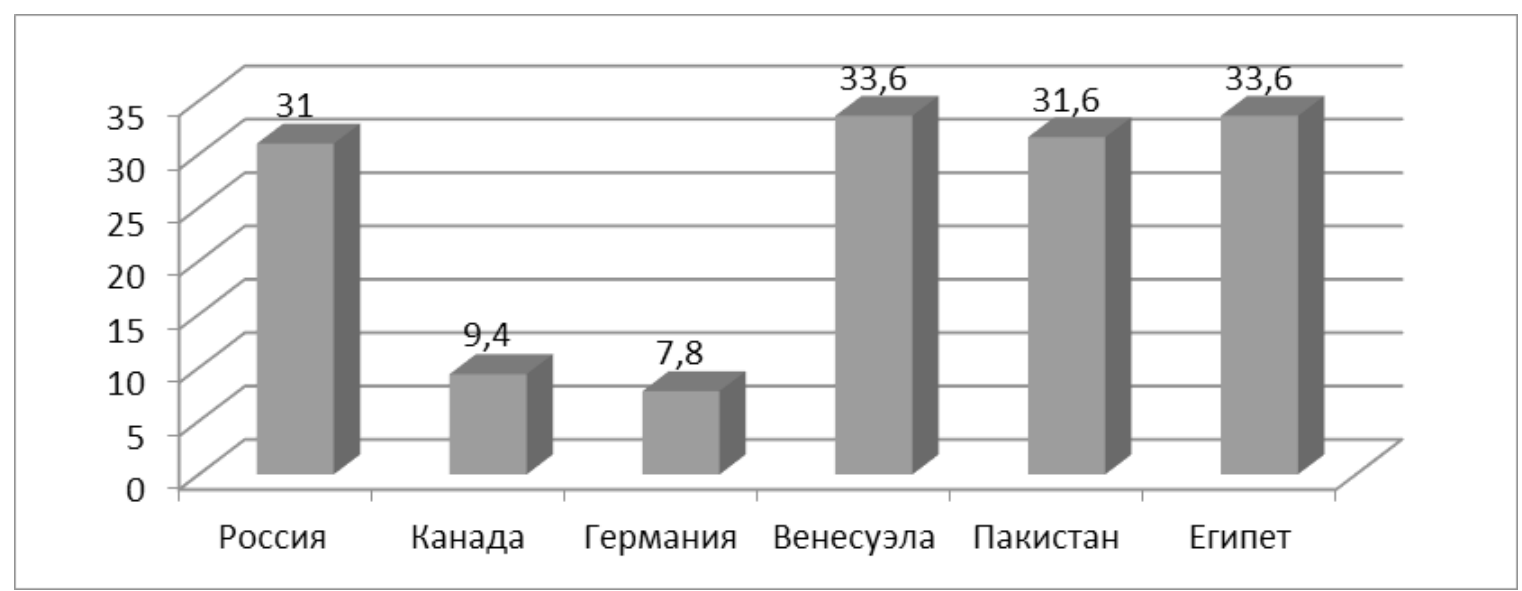

Рис. 7. Объемы теневой экономики в России и других стран по данным МВФ в 2019 году,\%

система является не до конца проработанной и совершенной. Имеет место множество противоречий, влекущих сложности в начислении и возможности уклонения от налоговых платежей. А это негативно сказывается на налоговом климате страны, поскольку выводит высокую долю экономики в «тень». Опираясь на данные межстранового исследования, представленные МВФ объемы теневой экономики в России намного выше оценок других стран (рисунок 7) [6].

Показатель в Росси выше среднего по 158 странам (27,8\%). Объем теневой экономики в РФ оказался сопоставим с Венесуэлой (33,6\%), Египтом (33,3\%) и Пакистаном (31,6\%), что определяет высокую значимость проблемы.
Теневой оборот в стране разделяется на криминальный и некриминальный. Некриминальный оборот в России обусловлен высокой долей неформально занятого, которая составляла на 2019 год 14,9 млн. человек, что 20,4\% в общей величины занятых официально. [5] При этом скрытый фонд оплаты труда в официальном и неофициальном секторах составил в 2019 году около 10,9 трлн. руб., или $11 \%$ ВВП.

Проведем анализ влияния теневого оборота на налоговый климат в стране (таблица 1).

Таким образом, снижение скрытого фонда оплаты труда и уменьшение объема теневого оборота, чего стремится добиться Правительство РРФ, в целом позво- 
Таблица 1. Анализ влияния теневого оборота на налоговый климат в РФ в 2020 году

\begin{tabular}{|c|c|c|c|}
\hline Показатель & 2019 год & 2020 год & Прогноз в 2021 году \\
\hline ВВП страны, трлн. руб. & 110,1 & 106,6 & 115,1 \\
\hline $\begin{array}{l}\text { Объемы теневой экономики } \\
\text { в России,\% }\end{array}$ & 31,0 & 29,0 & 25,0 \\
\hline $\begin{array}{l}\text { Потери в ВВП от теневой экономики, } \\
\text { трлн. руб. }\end{array}$ & 34,1 & 30,9 & 28,8 \\
\hline $\begin{array}{l}\text { скрытый фонд оплаты труда } \\
\text { в официальном и неофициальном } \\
\text { секторах, трлн. руб. }\end{array}$ & 10,9 & 9,7 & 8,9 \\
\hline $\begin{array}{l}\text { Снижение легального предложение } \\
\text { на рынке, трлн. руб. }\end{array}$ & 34,1 & 30,9 & 28,8 \\
\hline $\begin{array}{l}\text { Изменение легального спроса } \\
\text { на рынке, трлн. руб. }\end{array}$ & 10,9 & 9,7 & 8,9 \\
\hline $\begin{array}{l}\text { Влияние на макроэкономические } \\
\text { равновесие в целом, трлн. руб. }\end{array}$ & $-23,2$ & $-21,2$ & $-19,9$ \\
\hline
\end{tabular}

Источник: составлено автором по результатам проведенного опроса

лит уменьшить несбалансированность макроэкономического спроса и предложения. К тому же это позитивно скажется на ВВП страны, ее налоговых доходах, а значит и сделает налоговый климат страны более привлекательным.

\section{Результаты}

Основные проблемы, связанные с недостатками в налоговом климате РФ заключаются в следующем:

- недостаточная проработка отдельных элементов по начислению налогов, что позволяет использовать варианты незаконного уклонения от налогов в ряде случаев;

- высокая налоговая нагрузка на бизнес в виду недостаточного стимулирования и прозрачности налоговой системы;

- низкая степень гражданской ответственности, позволяющая принимать возможность уклонения от налогов, как данное, не акцентируя внимание на снижении налоговых доходов в стране.

Итак, в ходе проведения исследования было определено, что налоговый климат России имеет ряд проблем, негативно сказываемых на макроэкономическом равновесии экономики страны. Данное положение значительно усугубилось в 2020 году в результате пандемии, когда часть экономики была вынуждена прекратить или существенно уменьшить объемы своей деятельности. В этих условия правительству РФ важно проработать программу, которая с одной стороны будет стимулировать развитие бизнеса, а с другой - способствовать росту налоговых доходов бюджета.

Для решения выявленных проблем предложено:

- Внесение изменений в налоговый кодекс, значительное упрощение ряда статей;

- Разработка эффективной системы льгот и стимулирующих мер налогоплательщиков;

- Разработка программы по повышению гражданской ответственности в части уплаты налогов;

- Разработка прогрессивной шкалы имущественного налогообложения по опыту Германии;

- Дальнейшая интеграция прогрессивной шкалы в систему налогообложения физических лиц.

Внедрение предложенных решений будет способствовать развитию производства, импорт замещения, а также экспорта в России, повышению объема промышленности социальных отраслей экономки, а также привлечению новых инвестиций в экономику страны посредством участия ОЭЗ. В результате повыситься ВВП страны, а значит и улучшиться налоговый климат государства, что говорит о повышении стабильности экономики в целом. 


\section{ЛИТЕРАТУРА}

1. Ткач, Е.В. Перспективы развития налогообложения коммерческих организаций в контексте основных направлений бюджетной, налоговой и таможенно-тарифной политики на 2018 год и на плановый период 2019 и 2020 годов / Е.В. Ткач.— Текст: непосредственный // Вопросы экономики и управления.— 2018. — № 2 (13).—C. 9-12.

2. Фишер 0.В., Чанкселиани Л.Г. Формирование налогового климата территории как приоритетное направление региональной налоговой политики // Региональная экономика: теория и практика. 2012. № 18. URL: https://cyberleninka.ru/article/n/formirovanie-nalogovogo-klimata-territorii-kak-prioritetnoenapravlenie-regionalnoy-nalogovoy-politiki (дата обращения: 22.03.2021)

3. Комарова Е.И. Роль налоговой политики в формировании позитивного имиджа региона // Современные проблемы науки и образования.- 2015.№ 2-2.

4. Круговцова Е.В. Влияние уровня налогового бремени на экономическую привлекательность страны//Вопросы экономики и управления. — 2017. — № 4 (11). - C. $1-3$.

5. Левшукова 0.А., Петров Н.Р., Копнина А.И. Анализ масштабов развития теневой экономики в России // Вестник Академии знаний. 2019. № 3 (32). URL: https://cyberleninka.ru/article/n/analiz-masshtabov-razvitiya-tenevoy-ekonomiki-v-rossii (дата обращения: 09.02.2021).

6. Теневая экономика стран мира// http://fincan.ru/articles/95_tenevaja-ekonomika-stran-mira/(дата обращения: 09.02.2021).

(с) Савина Любовь Львовна ( Savina_LL@mail.ru)

Журнал «Современная наука: актуальные проблемы теории и практики»

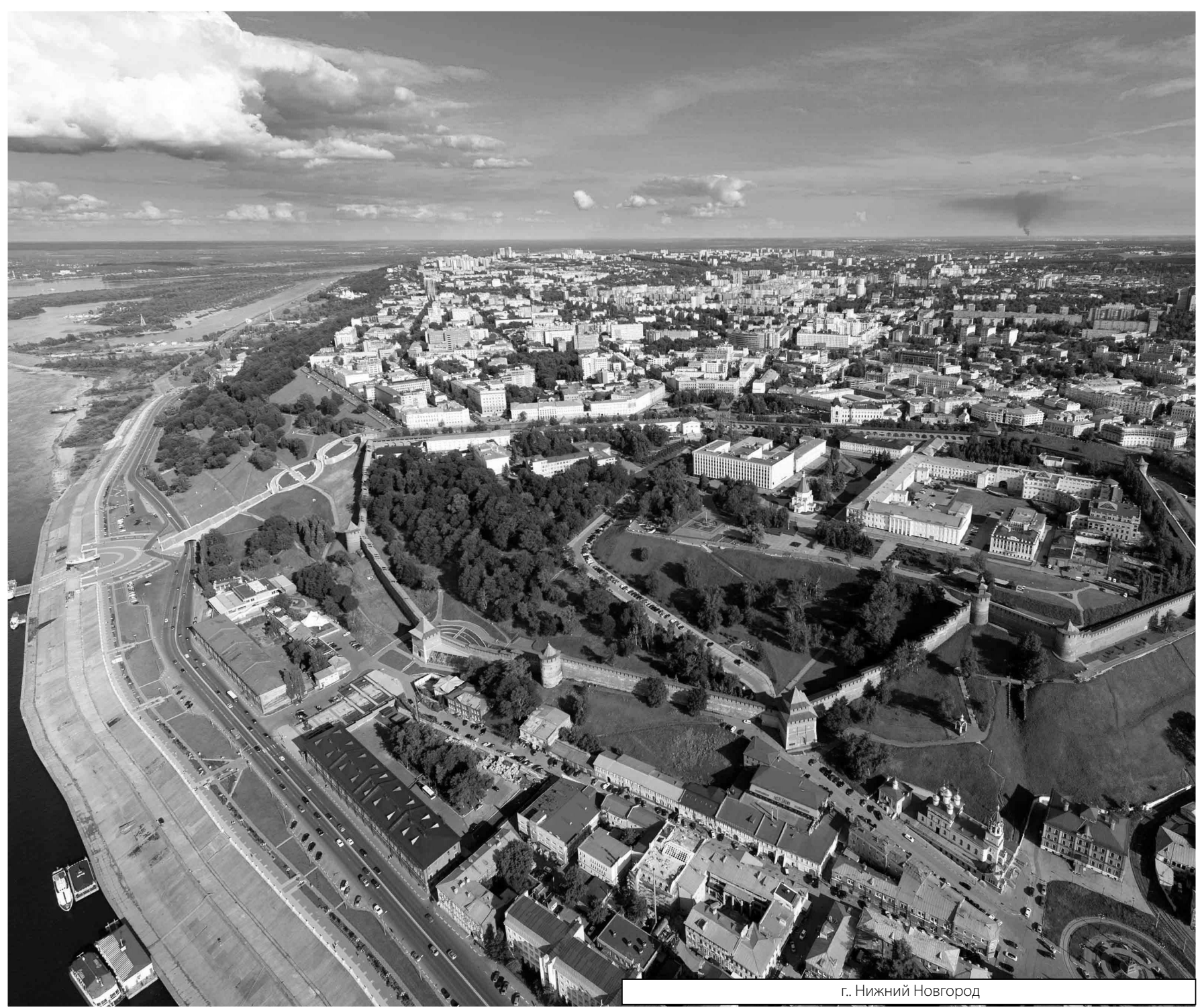

